\title{
Geometric Stability of Parts Produced by 3D Printing
}

\author{
Radomir MENDRICKY*, Rakeshkumar D. SONI
}

\begin{abstract}
The article focuses on an analysis of the long-term dimensional stability of parts produced by additive technology (using 3D printing). The models were already manufactured by different additive technologies such as FDM, PolyJet, SLS, and SLA a year ago. These models would be scanned using an ATOS II 400 3D contactless scanner and inspected by GOM Inspect Professional V8 depending on the principles of the 3D printing and optical digitisation. The parts were dimensionally and shape inspected 3 months after production, one year after production and one year after production with exposure to climatic tests (test-1: cyclic changes in the temperature and humidity, test-2: exposure to ultraviolet radiation). Then this analysis of measurement was compared with the CAD model and the printed model on the first day after printing. Based on this analysis, and from the point of view of ageing with respect to time, the technology and material that have a good dimensional and shape stability are discussed.
\end{abstract}

Keywords: additive technology; fused deposition modelling; geometric stability; PolyJet, selective laser sintering; stereolithography; 3D optical scanner; 3D digitisation

\section{INTRODUCTION}

Additive Manufacturing (AM) was developed for industrial applications due to its remarkable capabilities, such as building complex parts that are otherwise difficult to manufacture by conventional methods. AM is a layerby-layer automated fabrication process for making scaled 3-dimesional physical objects directly from 3D CAD data without utilising part-dependent implements. It was basically called "3D printing". AM can be subdivided into different techniques such as Stereolithography (SLA), Selective Laser Sintering (SLS), Fused Deposition Modelling (FDM), Selective Laser Melting (SLM), Laminated Object Manufacturing (LOM) and many more processes such as three-dimensional printing (3D printing) and PolyJet that have accessed the market. Today, AM is trending in all major industries such as the automotive and aerospace fields to medical implants, fashion and other fields (e.g., advanced craftsmanship and structural planning). Furthermore, AM is applicable in engineering and non-engineering fields and has domestic applications as well [1-3]. The advantages and disadvantages of each Rapid Prototyping (RP) process are dependent on the type of material and building styles utilised for the fabrication of the components. The material utilised in these processes include Acrylonitrile-Butadiene-Styrene (ABS), Polycarbonate (PC), photo-curable resin, polyamide, wax, metal/polymer/ceramic powders, adhesive coated sheets, etc. $[1,4]$. The quality of the RP material is adequate for limited scale applications, but does not always fulfil the quality and accuracy preconditions for vast applications for industrial purposes $[1,4,5]$.

During the research, a few additional studies concentrating on the technological details have been suggested, such as which parameters need to be set for the printing and which materials need to be used for the printing and material properties, and after the printing, what are the effects of the environmental conditions with respect to time [6-9]. Several studies can also be found in the available literature that have dealt with the influence of process parameters on the quality and accuracy of the FDM 3D printing technology [10-12], PolyJet Technology [13], SLM technology [14], or SLS technology [15].

In this paper, we mainly focus on the analysis of the long-term geometric stability of parts produced by additive technologies such as FDM, PolyJet, SLS and SLA. The models were already printed twelve months ago (hereinafter referred to as a "year") and were scanned by an ATOS II 400 3D contactless scanner and inspected by the GOM Inspect Professional software. All of these models were scanned and inspected at several time intervals, such as after 3 months, after a year and after a year with standard test-1 (i.e., temperature and humidity - one cycle runs for $720 \mathrm{~min}$ and the temperature ranges from $-40{ }^{\circ} \mathrm{C}$ to $+80{ }^{\circ} \mathrm{C}$ and the relative humidity ranges from $30 \%$ to $80 \%$ ) and test-2 (i.e., the ultraviolet lighting-outdoor cycle test is described in Tab. 1).

Table 1 Climatic test conditions for Outdoor - daytime

\begin{tabular}{|c|c|c|c|}
\hline Climate parameter & Unit & Dry climate & Humid Climate \\
\hline $\begin{array}{c}\text { Black standard } \\
\text { temperature }\end{array}$ & ${ }^{\circ} \mathrm{C}$ & (measured value) & $\begin{array}{c}\text { (measured } \\
\text { value) }\end{array}$ \\
\hline $\begin{array}{c}\text { Test chamber } \\
\text { temperature }\end{array}$ & ${ }^{\circ} \mathrm{C}$ & $42 \pm 3$ & $42 \pm 3$ \\
\hline $\begin{array}{c}\text { Rel. atmospheric } \\
\text { humidity }\end{array}$ & $\%$ & $<30$ & $>60$ \\
\hline Radiation intensity & $\mathrm{W} / \mathrm{m}^{2}$ & $1000 \pm 100$ & $1000 \pm 100$ \\
\hline
\end{tabular}

These measurements were compared with the CAD model and the printed model on the first day after printing. Based on these analyses, the dimensional and shape stability of additive manufacturing must be checked from the point of view of ageing overtime. In addition, some parameters were taken into account, such as the effect of the technology used, the 3D printer used, and the effect of test- 1 and test- 2 .

\section{METHODS AND MATERIALS}

\subsection{Manufacturing the Test Sample}

The model, as shown in Fig.1, was already designed in CAD software a year ago. Based on the designed 3D CAD model, a further description was made with respect to the dimensions and measurable parameters by scanning and inspection with the help of the GOM Inspect Professional V8 software. The measurable parameters were the diameters of sphere 1 , sphere 2 , sphere 3 , the spacing between two spheres, the diameters of inner cylinder 1, cylinder 2, cylinder 3 , outer cylinder 4 and the flatness, horizontal and vertical dimensions. 


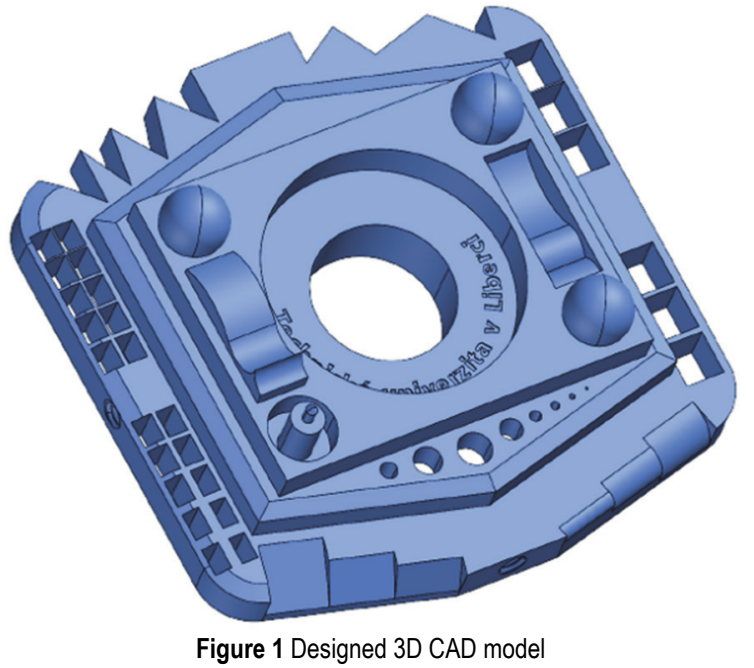

All these things are represented in the form of a 2D drawing of the CAD model with inspection labels in Fig. 2.

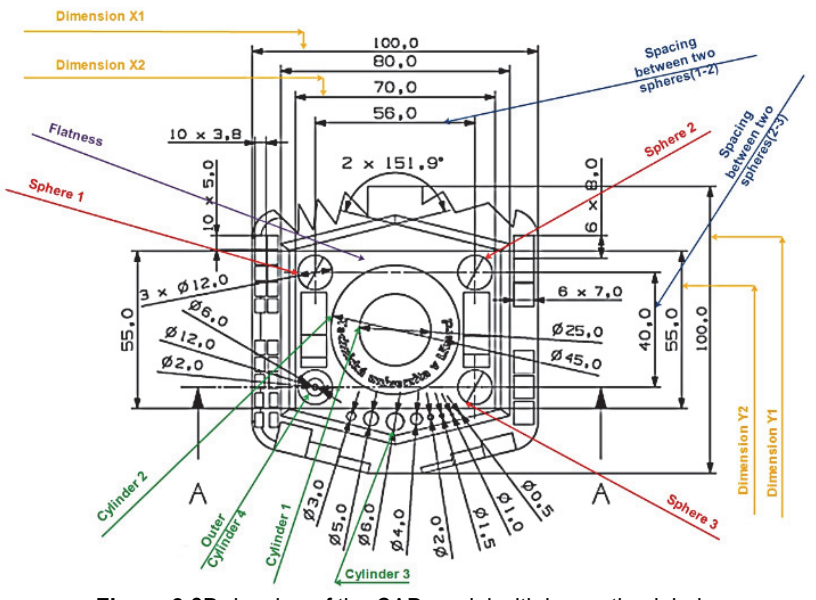

Figure $22 \mathrm{D}$ drawing of the $\mathrm{CAD}$ model with inspection labels

Table 2 Description of the manufacturer's printer and material and the standard test

\begin{tabular}{|c|c|c|c|c|c|}
\hline No. & Printer & Material & $\begin{array}{c}\text { Layer } \\
\text { thickness } \\
/ \mathrm{mm}\end{array}$ & Model & Test \\
\hline 1 & $\begin{array}{c}\text { FDM } \\
\text { Dimension }\end{array}$ & ABS-P400 & 0.25 & Full Solid & 2 \\
\hline 2 & $\begin{array}{c}\text { FDM } \\
\text { Dimension }\end{array}$ & ABS-P400 & 0.25 & Sparse light & 1 \\
\hline 3 & FDM Fortus & ABS-M30 & 0.25 & Full Solid & 1 \\
\hline 4 & FDM Fortus & ABS-M30 & 0.25 & Sparse light & 2 \\
\hline 5 & $\begin{array}{c}\text { PolyJet Object } \\
500\end{array}$ & Vero Grey & 0.016 & Matt & 2 \\
\hline 6 & $\begin{array}{c}\text { PolyJet Object } \\
500\end{array}$ & Vero Grey & 0.016 & Glossy & 1 \\
\hline 7 & $\begin{array}{c}\text { SLS EOSint } \\
\text { P395 }\end{array}$ & PA 2200 & 0.1 & $\begin{array}{c}\text { Vertically } \\
\text { printed }\end{array}$ & 2 \\
\hline 8 & $\begin{array}{c}\text { SLS EOSint } \\
\text { P395 }\end{array}$ & PA 2200 & 0.1 & $\begin{array}{c}\text { Horizontally } \\
\text { printed }\end{array}$ & 1 \\
\hline 9 & $\begin{array}{c}\text { SLA Form 2 } \\
\text { White Resin }\end{array}$ & 0.05 & $\begin{array}{c}\text { Full model } \\
\text { TUL }\end{array}$ & 2 \\
\hline 10 & SLA Ultra 3SP & $\begin{array}{c}\text { ABS 3SP } \\
\text { Tough }\end{array}$ & 0.05 & $\begin{array}{c}\text { Full model } \\
\text { Out side }\end{array}$ & 1 \\
\hline
\end{tabular}

These parts were manufactured by different Additive technologies such as FDM, PolyJet, SLS and SLA with different materials and structure of printing. Each sample was made twice for a total of 20 samples. The manufacturer's properties of the printer and materials are described in Tab. 2.

\subsection{Measurement Methods and Equipment Used}

In order to inspect the shape and dimensional precision of the manufactured part, the whole part had to be comprehensively measured. Currently, Optical 3D measuring technologies and full-filed surface measurement systems have become standard tools in virtually all industries worldwide. Those methods provide several significant advantages when compared to other conventional methods. Due to the high data density, they enable one to obtain a real 3D model of objects with complex shapes with high precision [4]. In this paper, an ATOS II 400 optical contactless 3D scanner manufactured by GOM was used (Fig. 3) [16].

The technical parameters of this scanner are shown in Tab. 3. The ATOS 3D scanner is 3D coordinate measuring machine with high degree of flexibility. The fast, noncontact, optical 3D scanner delivers a high-resolution point cloud which precisely describes free-form surfaces, finishes, and geometries. The sensor forms the basis for a diverse range of measuring tasks - from simple 3D scanning to fully automated measurement and inspection processes. The ATOS Essential line with the GOM Scan software is designed for simple scanning tasks. Its focus is on $3 \mathrm{D}$ scans of high data quality for applications such as reverse engineering or rapid Prototyping [17].

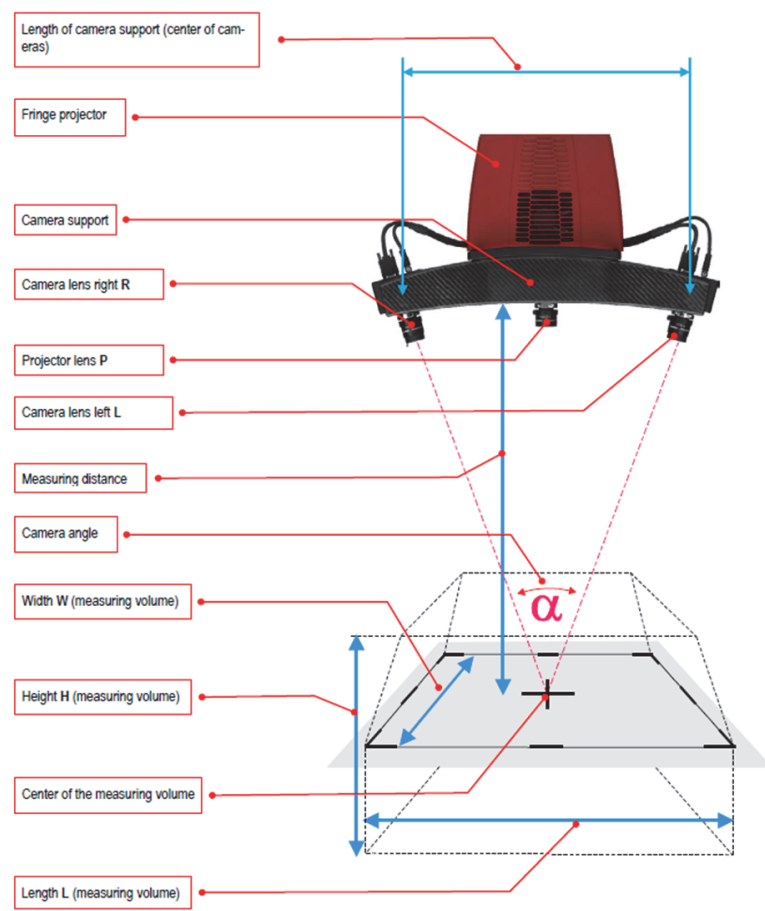

Figure 3 ATOS optical scanner with the definition of the terms referring to the sensor unit [17]

The ATOS system is based on the triangulation principle: The sensor unit projects different fringe patterns on the object to be measured and observes them by two cameras. Based on the optical transformation equations, the computer automatically calculates the $3 \mathrm{D}$ coordinates for each camera pixel with high precision. According to the Acceptance Test by GOM, the maximum measurement deviation of the said device is $0.017 \mathrm{~mm}$ for the "Sphere Spacing Error" parameter and $0.004 \mathrm{~mm}$ for the "Probing Error (Max. Sigma)". 
Table 3 Technical Parameters of the ATOS II 400 optical scanner

\begin{tabular}{|c|c|}
\hline \multicolumn{2}{|c|}{ ATOS II 400 Optical Scanner } \\
\hline Weight & $5.2 \mathrm{~kg}$ \\
\hline Dimensions & $490 \times 260 \times 170 \mathrm{~mm}$ \\
\hline Time of 1 scan & 1 second \\
\hline Measured Volume & $250 \times 200 \times 200 \mathrm{~mm}$ \\
\hline Resolution & $1800000 \mathrm{px}$ \\
\hline Point density & $0.18 \mathrm{~mm}$ \\
\hline Measurement error & max. $0.03 \mathrm{~mm}$ \\
\hline
\end{tabular}

When scanning, first set the cameras ideally at an angle of $45^{\circ}$ to the table top and scan a sufficient number of images within $360^{\circ}$ (in our case, 14 positions were used). The digitisation process of the inspected sample is shown in Fig. 4. Depending on the camera resolution, a point cloud of up to 4 million surface points results for each individual measurement.

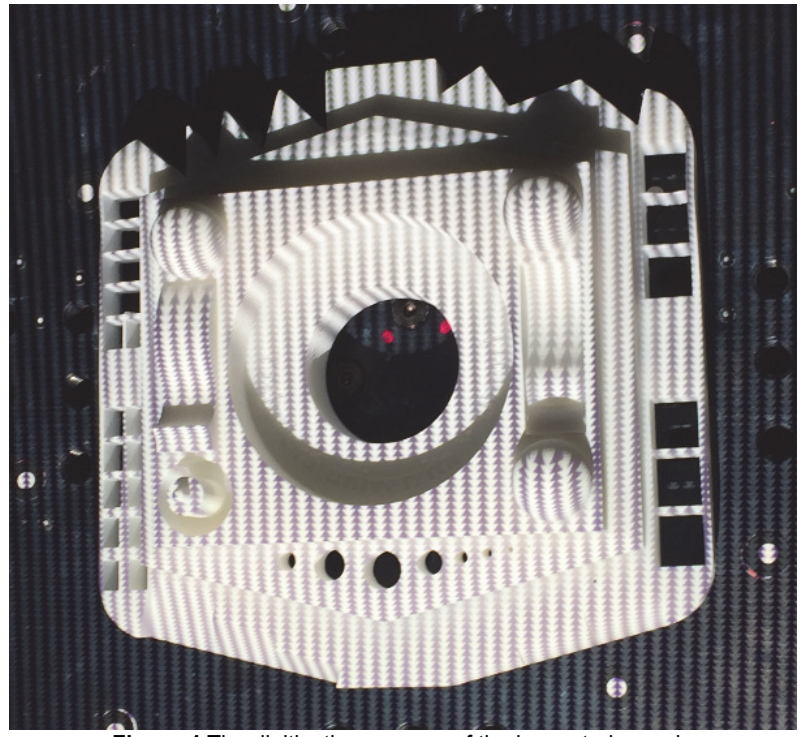

Figure 4 The digitisation process of the inspected sample

After digitising an object; many individual measurements from various views are required. The transformation into a global coordinate system is performed automatically by means of the reference points. Each individual measurement completes the building-up of the $3 \mathrm{D}$ model of the object to be scanned. In addition, the unnecessary part should be removed from the scanned model, and then the scanned part will be converted into an STL file. It gives a better quality visualisation.

\subsection{Analysis of Manufacturing Accuracy}

After scanning the models and converting the files into STL ones, the measurement of the dimensions was undertaken with the help of the GOM Inspect Professional V8 software. The Pre-alignment function was used to initialise the alignment of the models. Basic geometrical elements (cylinders, spheres, planes, etc.) were calculated by interlacing the fitting elements with Gauss Best-fit for $3 \sigma$. Here, some dimensions like the sphere's diameter, the spacing between two spheres and the inner cylinders, the outer cylinder with cylindricity were measured (Fig. 5 and Fig. 6). The figures illustrate that the nominal dimensions mean the CAD data and actual dimensions mean the scanned data with deviations.

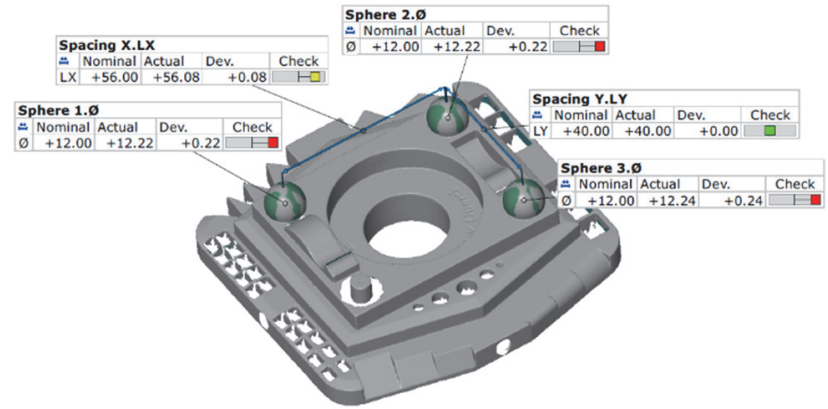

Figure 5 An example of the measured dimensions - inspection of the sphere diameters and their spacing (PolyJet - No. 5 after a year vs. CAD)

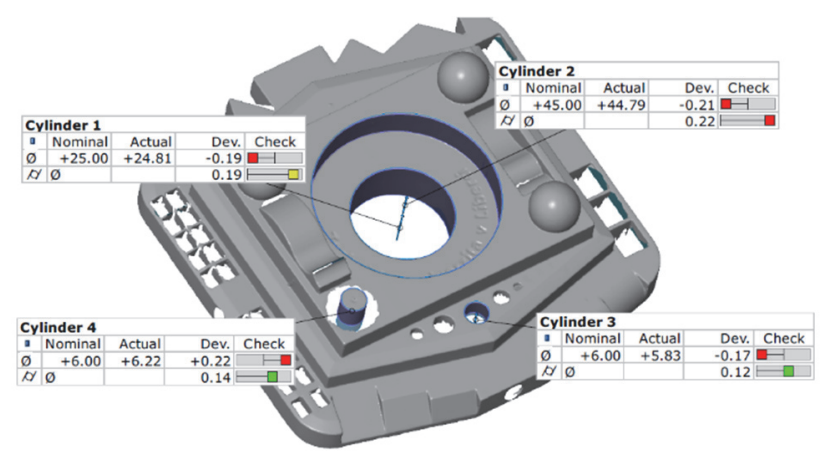

Figure 6 An example of the measured dimensions - inspection of the cylinder diameters (PolyJet - No. 5 after a year vs. CAD)

The flatness of the models was evaluated by the GOM Inspect Professional software after one year and test 1 and 2 , and the results can be seen in Fig. 7. The largest deviations were measured in the SLA-10 sample, in the range of +0.18 and $-0.10 \mathrm{~mm}$. Furthermore, the external dimensions of the parts (Dimension $X 1$ and $Y 1$ ) were checked.

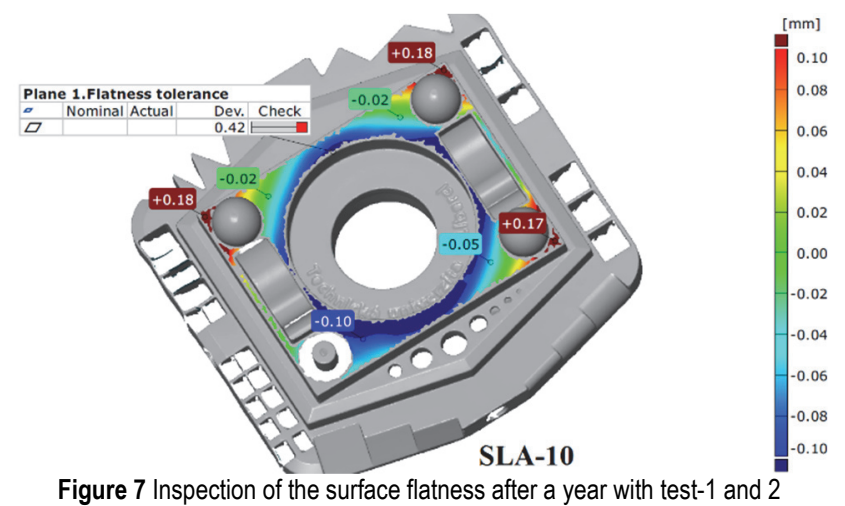

In this research, 10 types of models manufactured by different technologies, equally split between FDM, PolyJet, SLS and SLA have been used with different printing structures. Furthermore, this inspection was compared with the measured dimension on the CAD model and on the model on the first day after printing. Here, the average deviation values were calculated and divided into two groups. Those with values less than $0.05 \mathrm{~mm}$, which was considered a measurement error, and those with values more than $0.05 \mathrm{~mm}$, which was considered a model's error, which means they do not have good dimensional stability over time. The results mentioned below show the average deviations with the time duration after the manufacturing of the part, such as 3 months, after a year and after a year with test- 1 and 2 . 
Fig. 8 shows the diameters of the spheres and it is clearly defined that, in Polyjet-6, SLS-8 and SLA-10, there was good dimensional stability (deviation less than 0.05 $\mathrm{mm}$ ) after a year, but after testing with the standard test-1 and test-2, it shows that there has been some increase in the deviations (more than $0.05 \mathrm{~mm}$ ), which means that there is no dimensional stability after one year and the tests. On the other side, the remaining models such as the FDM Dimension-1 and -2, FDM Fortus-3 and -4, Polyjet-5, SLS7 and SLA-9, had good dimensional stability (less than $0.05 \mathrm{~mm}$ in deviations) throughout time.

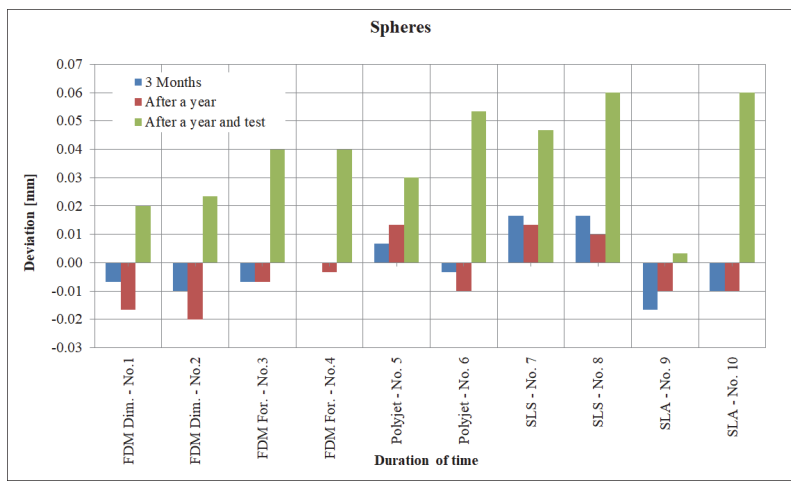

Figure 8 Average deviations of the spheres over time

In Fig. 9, it can be seen that, in Polyjet-6 and SLA-9, there were not any changes in the deviations of more than $\pm 0.05 \mathrm{~mm}$ up to a year, which means good dimensional stability up to a year, but after using the standard test- 1 and -2 , some sudden increase in the deviation of the dimensions could be seen, which were more than $\pm 0.05 \mathrm{~mm}$ (no longer any dimensional stability after a year with test-1 and -2). Additionally, in SLA-10, there was good dimensional stability up to 3 months, but after a year and after a year with test-1, the deviation values increased, so that there was not any good dimensional stability throughout time. On the other hand, the remaining models such as the FDM Dimension-1 and -2, FDM Fortus-3 and -4, Polyjet-5 and SLS-7 and -8 had good dimensional stability because the values of the deviation were below $\pm 0.05 \mathrm{~mm}$ throughout time.

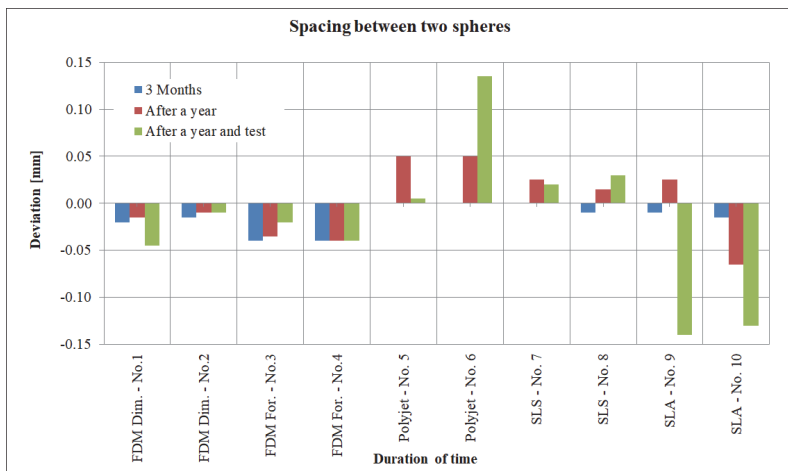

Figure 9 Average deviations of the spacing between two spheres over time

It can be seen from Fig. 10 that the deviation values for FDM Fortus-4, Polyjet-6 and SLA-9 and -10 were more than $\pm 0.05 \mathrm{~mm}$, which could be considered as no longer having dimensional stability throughout time. Though in some cases, the value of deviation was below $\pm 0.05 \mathrm{~mm}$ up to a year, after performing standard test- 1 and -2 , bad dimensional stability was observed in the models. Apart from this, the models such as FDM Dimension-1 and -2, FDM Fortus-3, Polyjet-5 and SLS-7 and -8 had no deviation changes of more than $\pm 0.05 \mathrm{~mm}$ during the entire time.

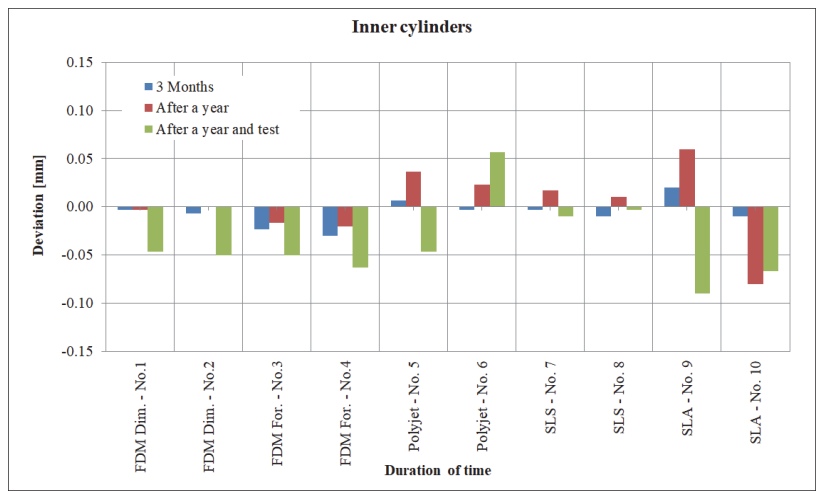

Figure 10 Average deviations of the inner cylinders over time

Fig. 11 indicates some minor changes in the outer cylinder or sometimes no deviations up to a year, but after using standard test- 1 and -2 , the outer diameter of cylinder was increased or decreased. It is clear from Fig. 11 that the deviation values were not more than $\pm 0.05 \mathrm{~mm}$ during the entire time, which means good dimensional stability over time in all the models.

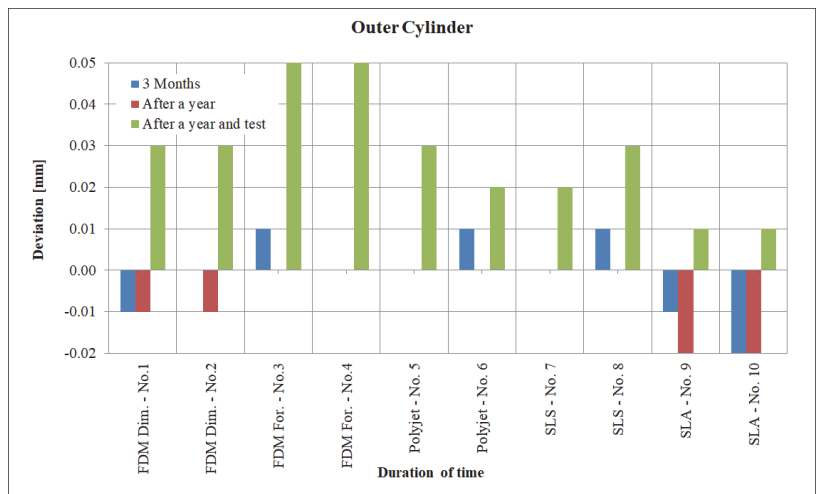

Figure 11 Average deviations of the outer cylinder over time

Fig. 12 depicts the average deviation in the cylindricity over time, such as 3 months, after a year and after a year with test- 1 and -2 compared with the $1^{\text {st }}$ day of printing. From this figure, it can be seen that, in all the models, there were some minor changes (less than $\pm 0.02 \mathrm{~mm}$ in deviations) and sometimes they remained constant over time.

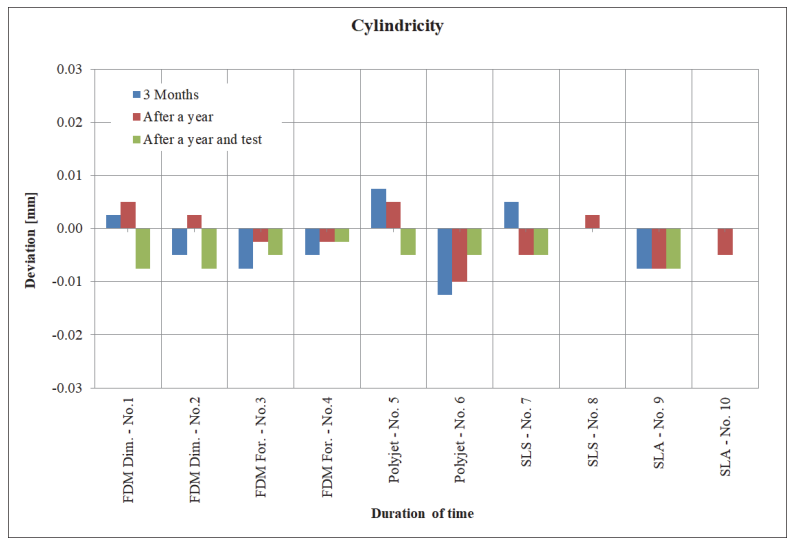

Figure 12 Average deviations in the cylindricity over time 
Fig. 13 shows the average deviation values of the flatness over time. In SLA-10, there was a constant deviation value of $0.02 \mathrm{~mm}$ up to a year, but once the standard test-1 was performed, deviations were observed (peak value $0.29 \mathrm{~mm}$ deviation). Based on this, it can be said that the dimensional stability was not good throughout time. Furthermore, in SLA-9, the deviation value increased day by day up to $0.10 \mathrm{~mm}$ over time ( 3 months, after a year and after a year with test-2). In Polyjet-6, no deviations were observed between 3 months and after a year, but after conducting standard test-1, the deviation increased up to $0.06 \mathrm{~mm}$. Hence, it could be said the models did not have good surface flatness stability over time. On the contrary, the deviation values did not change more than $\pm 0.05 \mathrm{~mm}$ for all the remaining models (good dimensional stability over time -3 months, after a year and after a year with test1 and 2).

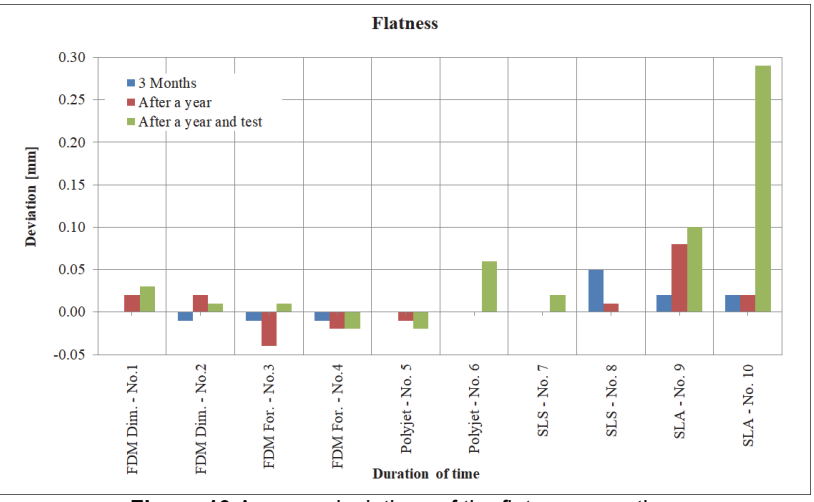

Figure 13 Average deviations of the flatness over time

The value in the deviation for Polyjet-6 and SLA-9 changed by up to $0.08 \mathrm{~mm}$ between 3 months and after a year (Fig. 14). However, the standard test- 1 and -2 rapidly increased and decreased the deviation up to 0.20 and -0.14 $\mathrm{mm}$, respectively (not good dimensional stability in the horizontal and vertical dimensions over time). In addition, the SLS-7 and -8 deviation values increased day by day up to 0.07 and $0.08 \mathrm{~mm}$ (not good dimensional stability in the horizontal and vertical dimensions over time).
Furthermore, in FDM Dimension-3 and -4, Polyjet-5 and SLA-10, there were changes in the deviation values, i.e., more than $\pm 0.05 \mathrm{~mm}$ up to a year. After that, standard test1 and -2 were conducted, which showed a sudden decrease in the deviation values $( \pm 0.05 \mathrm{~mm})$. This means there was not any good dimensional stability over time. In the last remaining models, like FDM Dimension-1 and -2, the deviation values were under $\pm 0.05 \mathrm{~mm}$ (good dimensional stability over time).

In the end, the result of model SLA No. 10 after a year with test-1 can be observed, as shown in Fig. 15. It is clear from Fig. 15 that after performing test-1 for temperature and humidity, a crack was generated (marked area).

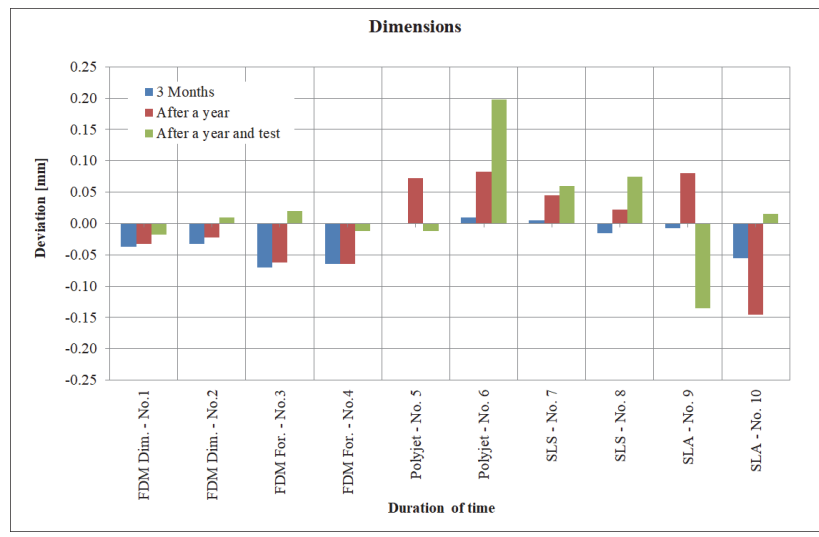

Figure 14 Average deviations in the dimensions over time

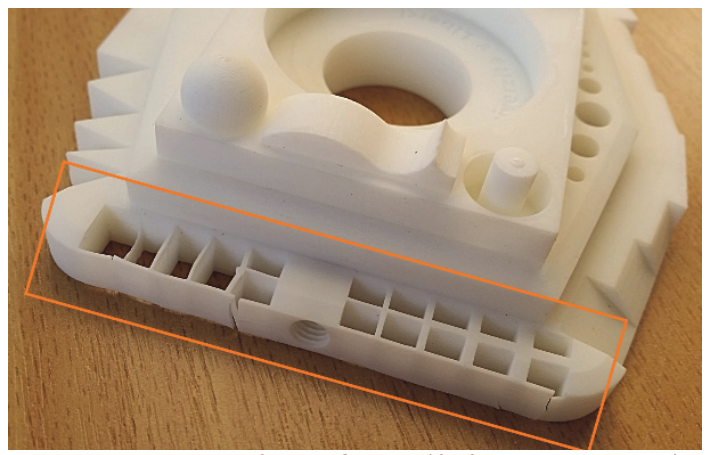

Figure 15 The result of model SLA No.10 after a year with test-1

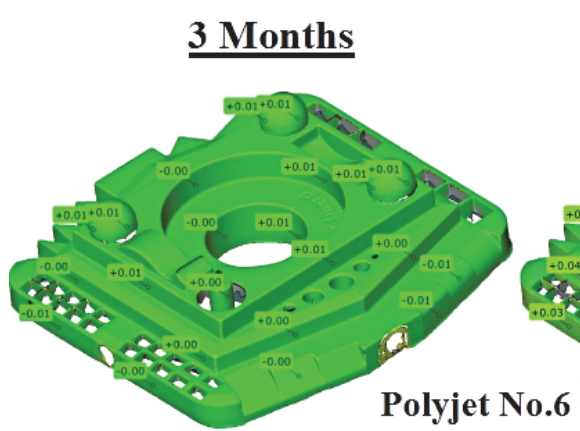

$\underline{\text { After a year }}$

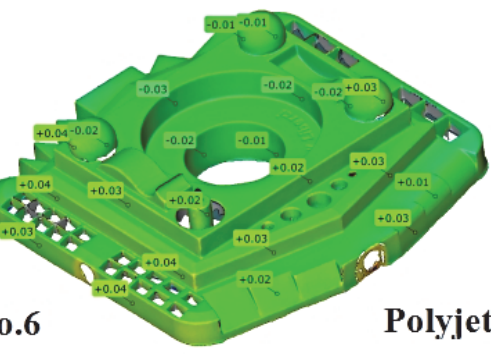

Polyjet No.6
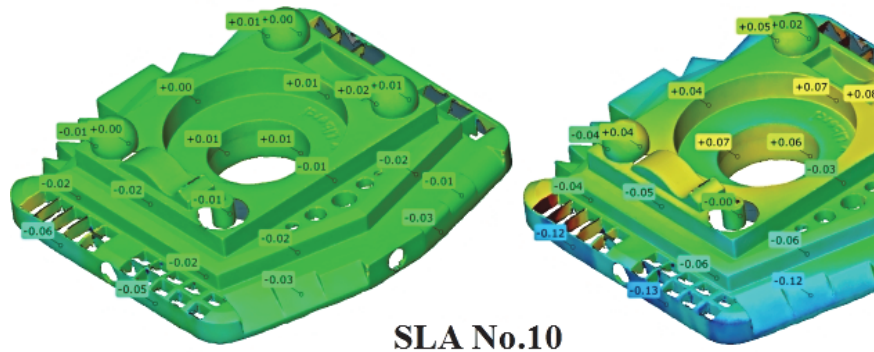

$+0.07$
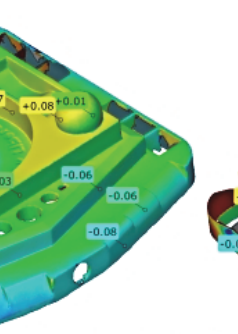

SLA No.10

Figure 16 Colour maps of the deviations (after 3 months, a year, a year and test- 1 ) from the printed model on the first day after printing 

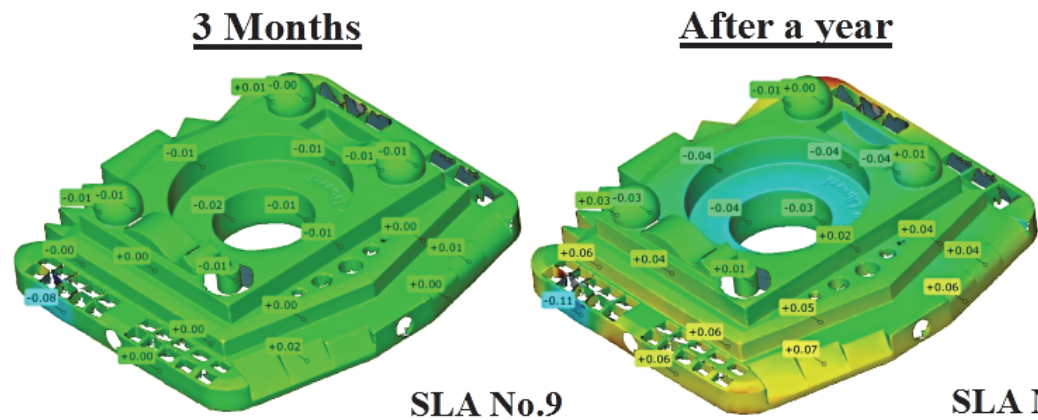

SLA No.9

\section{After a year and test-2}

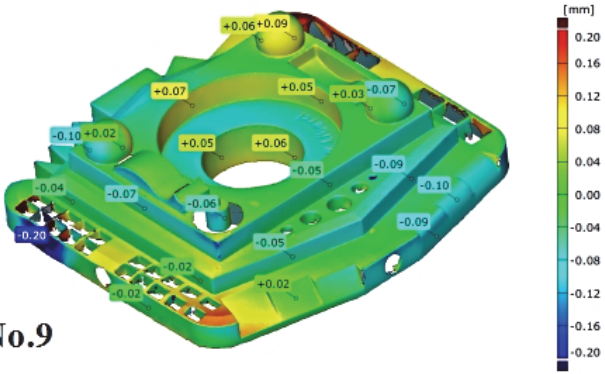

Figure 17 Colour maps of the deviations (after 3 months, a year, a year and test-2) from the printed model on the first day after printing

Figs. 16 and 17 show the colour maps in the deviations of the printed models (after 3 months, a year, a year and the standard tests) from the printed model on the first day after printing. The BestFit function was used to align both models. It can be clearly seen that, in Polyjet-6, there was no change up to a year, but after test-1 was performed, there was a change in the deviation which is represented by the different colours (Fig. 16). In SLA-9 and -10, there were changes between 3 months and after a year, but after standard tets- 1 and -2 were conducted, there were more changes in the dimensions (Fig. 16 and Fig. 17). Based on these colour maps and analyses, it could be said that there was not any good dimensional stability in these parts.

\section{CONCLUSION}

The main theme of this article was to inspect the dimensional stability of models produced by additive technologies such as FDM, PolyJet, SLS and SLA with different 3D printing structures. The models were scanned and inspected by the ATOS II 400 3D contactless scanner and GOM Inspect Professional V8 software. The scanning and inspecting were performed over time, i.e., 3 months, after a year and after a year with standard test- 1 (Humidity and Temperature) and standard test-2 (UV lighting). The parameters, such as the diameter of the spheres, the spacing between two spheres, the diameter of the inner and outer cylinder, the cylindricity, the flatness of the surface and the horizontal and vertical dimensions, were repeatedly measured on the models at each monitored time stage. Additionally, these measurement data were graphically compared with the printed model on the first day after printing. Based on these data comparisons, the deviations were divided into two groups, less than $0.05 \mathrm{~mm}$, which could be considered as measurement errors, i.e., a layer of spray painting, and more than $0.05 \mathrm{~mm}$, which was recognised as not having good dimensional stability over time.

Overall, all the measured parameters showed changes in the deviation (more than $0.05 \mathrm{~mm}$ ) in Polyjet-6 and SLA-10, so that there was no longer any good dimensional stability over time. Based on this analysis and theory, it could be said that some changes occurred in the material properties, weight loss, water absorption and shrinkage of surface material due to the performed standard test- 1 of humidity and temperature. In addition, for the SLA-9 model, all the measured parameters showed deviations of more than $0.05 \mathrm{~mm}$. Based on this analysis and theory, it could be said that, in SLA-9, there was not any good dimensional stability over time due to changes in the material properties, reduced ductility, changes in the surface colour and cracking due to the performed standard test- 2 of UV lighting.

Apart from this, all of the remaining models, such as FDM Dimension-1 and -2, FDM Fortus-3 and -4, Polyjet5 and SLS-7 and -8, that there were not any changes in the deviations of more than $\pm 0.05 \mathrm{~mm}$ over time. Based on this analysis, it could be said that there was good dimensional stability over time.

\section{Acknowledgements}

This work was supported by the Student Grant Competition of the Technical University of Liberec under the project Optimization of manufacturing systems, 3D technologies and automation No. SGS-2019-5011.

\section{REFERENCES}

[1] Gebhardt, A. \& Hötter, J.-S. (2016). Additive Manufacturing: $3 D$ Printing for Prototyping and Manufacturing. Hanser Publications. https://doi.org/10.3139/9781569905838

[2] Islam, M. N., Boswell, B., \& Pramanik, A. (2013). An Investigation of Dimensional Accuracy of Parts Produced by Three-Dimensional Printing. Proceedings of the World Congress on Engineering 2013, 1, 522-525.

[3] Kannan, T. R. (2014). Recent Additive Manufacturing Trends. Geometric Ltd.

[4] Du, W., Bai, Q., \& Zhang, B. (2016). A Novel Method for Additive/Subtractive Hybrid Manufacturing of Metallic Parts. Procedia Manufacturing, 5, 1018-1030. https://doi.org/10.1016/j.promfg.2016.08.067

[5] Guo, N. \& Leu, Ming C. (2013). Additive manufacturing: Technology, applications and research needs. Frontiers of Mechanical Engineering, 8(3), 215-243. https://doi.org/10.1007/s11465-013-0248-8

[6] Bakshi, K. R. \& Mulay, A. V. (2016). A Review on Selective Laser Sintering: A Rapid Prototyping Technology. IOSR Journal of Mechanical and Civil Engineering, 04(04), 53-57. https://doi.org/10.9790/1684-15008040453-57

[7] Kwon, D., Park, E., Ha, S., \& Kim, N. (2017). Effect of humidity changes on dimensional stability of 3D printed parts by selective laser sintering. International Journal of Precision Engineering and Manufacturing, 18(9), 12751280. https://doi.org/10.1007/s12541-017-0150-0

[8] Soni, D. R. (2018). Dimensional stability of parts manufactured by additive technologies. Doctoral thesis, Technical university of Liberec.

[9] Mendřický, R. \& Friš, D. (2020). Analysis of the Accuracy and the Surface Roughness of FDM/FFF Technology and Optimisation of Process Parameters. Tehnički vjesnik, 27(4), 1166-1173. https://doi.org/10.17559/TV-20190320142210 
[10] Raol, T. S., Dave, D. K. G., Patel, D. B., \& Talati, V. N. (2014). An Experimental Investigation of Effect of Process Parameters on Surface Roughness of Fused Deposition Modeling Built Parts. International Journal of Engineering Research \& Technology (IJERT), 3(4), 2270-2274.

[11] Pérez, M., Medina-Sánchez, G., García-Collado, A., Gupta, M., \& Carou, D. (2018). Surface Quality Enhancement of Fused Deposition Modeling (FDM) Printed Samples Based on the Selection of Critical Printing Parameters. Materials, 11(8), 1382. https://doi.org/10.3390/ma11081382

[12] Nancharaiah, T., Ranga Raju, D., \& Ramachandra Raju, V. (2010). An experimental investigation on surface quality and dimensional accuracy of FDM components. International Journal on Emerging Technologies, 1(2), 106-111.

[13] Gay, P., Blanco, D., Pelayo, F., Noriega, A., \& Fernández, P. (2015). Analysis of Factors Influencing the Mechanical Properties of Flat PolyJet Manufactured Parts. Procedia Engineering, 132, 70-77. https://doi.org/10.1016/j.proeng.2015.12.481.

[14] Keller, P. \& Mendricky, R. (2015). Parameters Influencing the Precision of SLM Production. MM Science Journal, 2015(03), 705-710. https://doi.org/10.17973/MMSJ.2015_10_201540

[15] Dadbakhsh, S., Verbelen, L., Vandeputte, T., Strobbe, D., Van Puyvelde, P., \& Kruth, J.-P. (2016). Effect of Powder Size and Shape on the SLS Processability and Mechanical Properties of a TPU Elastomer. Physics Procedia, 83, 971980. https://doi.org/10.1016/j.phpro.2016.08.102

[16] Mendricky, R. (2016). Determination of Measurement Accuracy of Optical 3D Scanners. MM Science Journal, 2016(06), 1565-1572. https://doi.org/10.17973/MMSJ.2016_12_2016183

[17] GOM, mbH. (2010). ATOS v7-Hardware: User manual. Braunschweig, Germany.

\section{Contact information:}

Radomir MENDRICKY, Ing., PhD

(Corresponding author)

Technical University of Liberec,

Faculty of Mechanical Engineering,

Department of Manufacturing Systems and Automatization,

Studentska 2, 46117 Liberec 1, Czech Republic

E-mail: radomir.mendricky@tul.cz

Rakeshkumar D. SONI, Ing.

Technical University of Liberec,

Faculty of Mechanical Engineering,

Department of Manufacturing Systems and Automatization,

Studentska 2, 46117 Liberec 1, Czech Republic

E-mail: rakesh_d_soni@yahoo.com 